\title{
Analysis of Patent Examination Effort Distribution based on the Queuing Theory
}

\author{
João Gilberto Sampaio (I), Suzana Borschiver (2)
}

\begin{abstract}
In this paper, we present a mathematical model based on the queuing theory that simulates the examination process in a patent office, including its relation with the applicants. Through this statistical model, this study aims at evaluating the examination effort distribution among all examination stages, in order to establish the optimal examination condition, which means that a patent application would be granted, denied or withdrawn in the shortest period of time and the backlog of patent offices would be reduced, meeting the society demand in a more efficient way. This study also aims at evaluating the performance of a specific patent examiner based on the optimal condition.
\end{abstract}

Keywords: queuing theory, patent examination effort distribution, decision profile, backlog.

(I) Brazilian Institute of Industrial Property (INPI-Br), Rua Mayrink Veiga, 9 - Centro, 19o Andar, CEP: 20.090-910, Rio de Janeiro, RJ, Brazil, Phone: +55 (2I)2I 39-3770, E-mail: jsampaio@inpi.gov.br / jgsfsilva@gmail.com

(2) Department of Chemical Engineering, Federal University of Rio de Janeiro, Bloco E - Sala E-204 - Ilha do Fundão, CEP 2I94I-909, Rio de Janeiro, RJ, Brazil, Phone: +55 (2I) 2562-7582, E-mail: suzana@eq.ufrj.br 


\section{Introduction}

One of the main drives of industry is innovation, generating new services and products to be offered to society, leading enterprises and countries to economic growth and competitive positions.

To ensure that this competitive advantage is sustainable, it is vital to protect innovations against illegal copying through the use of the patent system and patents itself. A patent application is a complex legal document that provides its owner with the monopoly on exploration of a particular technology for a limited period of time, and it is an instrument to prevent competitors from using the innovation developed and released by this document. Patents, as well as being used to establish a temporary privilege of use of a particular technology, are still considered an asset on commercial trades and technology licensing. They are also used to map the technological development of suppliers, competitors and customers and they are a criterion for evaluating investment in the stock market.

According to the USTPO (United States Patent and Trademark Office), the economy of the United States presented an increase of $100 \%$ in patent activity during the decades of 80 and 90 , reflecting the increase of innovation and technology activities in the North American economy (King, 200I). Considering the increasing number of patent applications and the growing complexity of these documents, more and more skill and time are needed to retrieve information from databases of technology data (Phillip, 2006), which leads to an increase in the patent examiners' workload (King 200I).

The first consequence of the work overload of the patent offices is the delay in analyzing and granting patents, which results in a backlog of patent applications to be examined. SINGH (2007) defines the term backlog of patent applications as the average amount of time that a patent application takes to be granted or denied, while the USPTO defines backlog as the period of time between the filing date and the date which the patent application is granted, denied or withdrawn.

The meaning of backlog may vary from patent office to patent office (GAO, 1996), as it does from the United States patent office to the European patent office (EPO) and the Japanese patent office (JPO). The USPTO considers that the examination process begins at the moment the patent application is filed and performs its backlog calculations based on the patent applications that are granted, denied or withdrawn, while the Japanese and European office consider that the examination process begins months or years after the filing and take account the patent applications that are being examined to calculate the backlog. This fact means that the simple comparison of backlog statistics information between different patent offices may not be meaningful.

Another consequence of the work overload is that there can be a reduction of examination quality and uncertainties regarding the intellectual properties rights (King, 2003). Once the time and effort invested by patent examiners are the bottlenecks for the examination of patent applications (King, 200I), applicants' and patent offices ${ }^{2}$ constantly work considering the restriction of time, and are often not able to perform a meaningful search in the state of the art, leading to both quality analysis and granting of patents of dubious nature. This situation is critical because it creates a vicious cycle which starts with an increasing number of patents of poor quality, which causes a greater difficulty in performing searches in the state of the art, which in turn results in the granting of more patents of low quality.

Despite the fact that the time spent on conducting an examination and consequently the examination capacity of a patent office are closely related to the quality of the examinations and quality of the patents granted, Batabyal and DeAngelo (2008) and Batabyal and Nijkamp (2008) indicate that when patent applications are examined in a rigorous way, with higher quality of examination and therefore taking more time, the patent office examination capacity does not necessarily reduce. However, these studies consider a restricted situation of patent analysis and do not represent the current problem which most patent offices face.

King (200I), on the other hand, establishes a statistical correlation between the elements related to the patent examiner and the examination process, determining which of these elements offer a greater contribution to the quality and quantity of patents granted. An important conclusion of this study, confirmed by King (2003), is the fact that the most important inputs to the examination process of patent applications are the number of hours that the patent examiners invest in performing the examination and the attention given by them to the patent application.

I It is called "applicants" the individuals or institutions responsible for writing and filing patent applications, who can be either an inventor or an attorney that represents an inventor.

2 It is called "patent offices" the institutions responsible for examining and granting patent applications, such as the Brazilian INPI (National Institute of Industrial Property), EPO (European Patent Office) or the USPTO (United States Patent and Trademark Office). 
King (2003) presents another relevant issue to the quality of the examination of patent applications: the procedures that the patent examiner follows to analyze the documents. Thus, both the time spent on the patent application examination and the procedures to carry out the analysis have an important role in determining the quality of the patent over time. Moreover, the different amounts of time spent on the examination of patent applications are mainly a consequence of the technological differences in the patent applications. These differences do not change much with the increasing experience of the patent examiners but with the complexity of the technological field (Popp, Juhl and Johnson, 2004), which makes it even more important to balance the productivity of the analysis and the quality of the examination.

Granting low quality patents results in additional problems for the patent system, such as the costs involving oppositions, lawsuits and payments of high fees for licensing of technology, leading to possible unfair enrichment by low quality patent holders and to an eventual delay and prevention of introduction of new services and products in the market. Nevertheless, low quality patents may also adversely affect the patent holders, once it is possible that after they make the necessary investments in the industry based on the technology patented, these patents be challenged and invalidated by one of their competitors. One way or another, the increase in costs leads to the reduction of the rate of innovation, the reduction of the economy based on patents and the average increase in market prices of patented goods and services.

To avoid a costly and time-consuming lawsuit, the instrument of opposition was created. The opposition is characterized by a request to review a decision ${ }^{3}$ of a patent application performed by a patent office, being this review still a technical examination performed within the patent office. This instrument has also the objective of reducing the incentive to defensive patents, which are a tool for reducing the rate of innovation (Hall and Ziedonis, 200I). When the results of the analysis and opposition of the patent application are not satisfactory for a party, then a lawsuit is held in court. Both the opposition and the lawsuit are based on the assumption that, if previous information disclosed by the state of the art is ignored by patent examiners, interested parties may challenge the validity of the low quality or dubious merit patents (Graham et al., 2003). In order to illustrate this situation, Barton (2000) shows that in the year 2000 the number of lawyers specialized in intellectual property in the United States grew more than research and development, and that the legal costs related to the examination and patent granting reached the average U.S. $\$ 10.000,00$ while the legal costs for the resolution of a lawsuit involving a patent reached the average value of U.S. $\$$ I.500.000,00.

Another impact of oppositions and lawsuits on the backlog is that, the more challenged the validity of patents are, the less available the patent examiners are for the examination of new patent applications, increasing the work overload in the patent offices.

In theory, the completion of the examination with criteria and attention reduces the need for a future review of the decisions of patent applications, by both the patent office and the court. Considering an ideal patent office, a patent granted would not be lately revoked and the scope of its protection would be perfectly defined, providing quality information for an eventual lawsuit. In this case, the reviewed and approved claims would have full conditions to reward the applicant by the importance of his invention, as well as providing information for the development of enhancements and other related inventions.

On the other hand, the low quality of patent applications examination and consequently the quality of the examination results lead to a divergence of opinions between the patent offices and the court decisions, resulting in a minor relevance of the patent application examination and the patent itself in court, which ultimately increases the uncertainty regarding the intellectual property rights, the capacity of return on investment in research and developmental activities and the request of privilege of patent (King, 2003).

The patent protection in these cases is guaranteed through a lawsuit or through negotiation held between the parties under the threat of a lawsuit, which means that the quality of the examination may reduce the amount of disputes, providing a higher efficiency in industries where the patent protection is vital for the business.

Meurer (1989) presents a study which indicates that the greater the uncertainty regarding the validity of the patent, the greater the occurrence of violations and lawsuits, being the validity of the patent related to the quality of the examination. King (2003) reinforces this conclusion when he indicates that the quality of the examinations of patent applications influences the quality of patents granted and therefore the incentives for violations against these rights. This means that the lower the quality of the examination of a granted patent, the greater the likelihood of this right not be sustained in court, which can lead to a greater number of infractions depending on the techno-

3 A patent application decision includes patent application granting or denying by the patent examiner and patent application withdrawing by the applicant. 
logical field and on the economic aspects involving the individuals that are affected by this specific market monopoly. This study also indicates that the quality of the examination would reduce the amount of patents reviewed in court, reducing the probability of lawsuits, bringing benefits to the individuals involved in the patent, providing more transparency and less uncertainty regarding intellectual property rights, creating incentives for innovation and decreasing the costs and workload of the legal system dedicated to judge intellectual property rights disputes.

To analyze the performance of the patent examination process, a statistical modeling strategy based on the queuing theory is proposed. Through this model, this study aims at evaluating the examination effort distribution among all examination stages ${ }^{4}$, in order to establish the optimal examination condition, which means that a patent application would be granted, denied or withdrawn in the shortest period of time. It also aims at evaluating the performance of a specific patent examiner based on the optimal condition. It is not an objective of this article to discuss patent quality, and it will be considered that all patent application examinations will be performed with quality.

\section{Queuing theory applied to patent examination mode- ling}

A system is defined by the queuing theory as a combination of a queue where several customers wait for a service, and a service, which can be provided by one or several servers processing the customers in the queue. Figure I illustrates a system with one server according to the queuing theory.

Considering a system with $m$ positions occupied by customers, being position 0 the service position provided by a single server, if a new customer arrives at the system, this customer will occupy position $m$, leaving the system with $m+l$ customers. Figure 2 illustrates a customer arrival in a single server system.

By the end of the processing, the customer that occupies position 0 leaves the system if the system is an open system, or return to the queue if the system is a closed system. When the customer leaves the service position, all customers in the queue move one position forward, and the customer occupying position I moves to position 0 and its processing starts.

It is important to underline that, for a specific system, there is an order to provide the service to the customers that is given by the order in which the customers arrive in the system.
Systems can mathematically be defined by $G / G / n$, in which the first $G$ represents a generic function that describes the customer arrival process to the queue, the second $G$ represents a generic function that describes the customer processing by the servers and $\mathrm{n}$ the number of servers processing customers. If the customer arrival and the services can be described as Poisson processes, the $G / G / n$ can be represented as an $M / M / n$ system.

Ross (2003) states that average properties can be defined for a system defined by the queuing theory: $L$, which represents the average number of customers in the system, $L_{Q}$, which represents the average number of customers in the queue, $W$, which represents the average amount of time that a customer remains in the system and $W_{Q}$, which represents the amount of time that a customer remains in the queue.

Considering an M/M/I open system, as in Figure 3, and assuming that customers arrive at the system with an average rate $\lambda$ according to a Poisson distribution, the average time between successive arrivals is $/ / \lambda$. If the queue is empty, the customer goes directly to the service position or waits in the queue if this position is already occupied. By the time the server finishes processing one customer, this customer leaves the system and the next customer, if there is any, enters the service position. The average time between successive periods of service, according to a Poisson distribution, is defined by $I / \mu$, where $\mu$ is the average rate of customer processing.

For an $M / M / /$ open system, the average properties of the system can be established as a function of the average customer arrival rate $\lambda$ and the average customer processing rate $\mu$, as in the following equations:

$$
\begin{aligned}
& L=\frac{\lambda}{\mu-\lambda} \\
& W=\frac{1}{\mu-\lambda} \\
& W_{Q}=\frac{\lambda}{\mu(\mu-\lambda)} \\
& L_{Q}=\frac{\lambda^{2}}{\mu(\mu-\lambda)}
\end{aligned}
$$

4 The "effort distribution among all examination stages" is the distribution of the limited work capacity of the patent examiner among the first, the second, the third, etc, examination stages. 
These equations are valid only if the relation $\lambda / \mu$ is less than $I$ $(\lambda / \mu<I)$, otherwise the number of customers in the system would be infinity.

For a system consisting of $P M / M / /$ subsystems in series, as in Figure 4, if the customer arrival in the first subsystem is defined by $\lambda$, the output of subsystem $j$ is the input of subsystem $j+I$ and the service rate of the $j^{\text {th }}$ subsystem is defined by $\mu_{j}$, the average properties for each subsystem can be defined as in the following equations (Ross, 2003):

$$
\begin{aligned}
& L_{j}=\frac{\lambda}{\mu_{j}-\lambda} \\
& W_{j}=\frac{1}{\mu_{j}-\lambda} \\
& W_{Q j}=\frac{\lambda}{\mu_{j}\left(\mu_{j}-\lambda\right)} \\
& L_{Q j}=\frac{\lambda^{2}}{\mu_{j}\left(\mu_{j}-\lambda\right)}
\end{aligned}
$$

As well as for a single system, these equations are valid only if each service rate $\mu_{j}$ is a higher value than the customer arrival rate $\mu$ at the first subsystem, which means that each relation $\lambda / \mu_{j}$ must be less than I $\left(\lambda / \mu_{j}<1\right)$, otherwise the number of customers in the series of subsystem would be infinity.

According to Burke's Theorem, the split of a Poisson process can be modeled as several parallel Poisson distributions (Bose, 2002). Figure 5 illustrates Burke's theorem applied to a division of a Poisson process.

For a division of a Poisson process, the sum of fractions pj of rate $\lambda$ must be equal to $I$, as in the following equation:

$$
\sum_{j=1}^{N} \rho_{j}=1
$$

This theorem considers a balanced system, which means that the input and the output rates of a subsystem $j$ are the same or, in other words, that the input and the output of subsystem $j$ are equal to $\lambda$ pj (Bose, 2002). If the input and output present equal rates, the service rate $\mu j$ of subsystem $j$ must be greater than the input rate $\lambda \mathrm{pj}$, which means that the relation between the input rate $\lambda$ pj and service rate $\mu$ j must be less than $I(\lambda \mathrm{pj} / \mu \mathrm{j}<I)$.
Burke's theorem can also be applied to a combination of Poisson processes (Bose, 2002), as in Figure 6.

A consequence of Burke's theorem would be the replacement of parallel Poisson processes of input rate of $\lambda$ pj and service rate of $\mu \mathrm{j}$, as in Figure 7, for a single equivalent Poisson process of input $\lambda$ and service rate of $\mu_{E Q}$, as in Figure 8.

Jackson's theorem (Bose, 2002) is a variation of Burke's theorem and considers that, for a system consisting of $M / M / I$ subsystems, each individual $M / M / I$ subsystem j can be considered an isolated system, and its average properties can be determined by equations 5 to 8 if this subsystem $j$ is in equilibrium. Being in equilibrium means that, for all subsystems, average input rate $\lambda j$, where $I \leq j \leq N$, must be lower than its average service rate $\mu$, which leads to the conclusion that the relation between the input rate $\lambda \mathrm{j}$ and the service rate $\mu \mathrm{j}$ must be lower than I $(\lambda j / \mu j<1)$. Also according to Jackson's theorem, these subsystems should behave as if they were independent, even if they are not fully independent, and the combined distribution must be obtained as a function of the individual distributions. At last, the process of customer arrival for each subsystem must be considered a Poisson distribution, even if it does not entirely behave as one.

Based on these theorems, it is possible to build a model for patent processing based on the queuing theory as a series of $M / M / I$ subsystems, as in Figure 9, where $P O$ represents a single patent examiner of the patent office, APP the applicants, $P$ the number of examination stages, $\lambda$ the average rate of new patent applications arrival in the first examination stage, $\mu_{\mathrm{j}}^{\mathrm{i}}$ the patent examination average rate of the $j^{\text {th }}$ stage of patent examination, $\mu^{D}$ the applicant answering average rate of the patent application examination performed during $j^{\text {th }}$ stage of patent examination and $p j$ the percentage of the rate of new patent applications arrival in the first examination stage $\lambda$ that are granted, denied or withdrawn after stage $j$ of patent examination.

This model considers that: a) the arrival of new patent applications is to be examined by one patent examiner, b) this patent examiner examines patent applications in several patent examination stages and, c) for each stage, the oldest patent applications have priority to be examined. This model also considers that between two patent examination stages there is an intermediate stage where the applicants have the opportunity to answer the patent examiner analysis, and that after each examination stage a percentage of the patent applications that are examined are granted or denied by the patent examiner or withdrawn by the applicants based on the examination performed by the patent examiner, then leaving the system. 
Although it is possible to extend this model to cover several patent examiners, its focus is on the technical work of a single patent examiner. The applicants are regarded, in this model, as being an equivalent single applicant, according to Burke's theorem. tablish the average number of patent applications $L$ in the system and the average period of time $W$ which a patent application takes from the moment it enters into the system to the moment it is granted, denied or withdrawn, as presented by the following equations:

Based on the model presented in Figure 9, it is possible to es-

$$
\begin{aligned}
& L=\lambda\left(\sum_{j=1}^{P} \frac{1-\sum_{i=1}^{j-1} \rho_{i}}{\mu_{j}^{I}-\lambda\left(1-\sum_{i=1}^{j-1} \rho_{i}\right)}+\sum_{j=1}^{P-1} \frac{1-\sum_{i=1}^{j} \rho_{i}}{\mu_{j}^{D}-\lambda\left(1-\sum_{i=1}^{j} \rho_{i}\right)}\right) \\
& W=\left(\sum_{j=1}^{P} \frac{1-\sum_{i=1}^{j-1} \rho_{i}}{\mu_{j}^{I}-\lambda\left(1-\sum_{i=1}^{j-1} \rho_{i}\right)}+\sum_{j=1}^{P-1} \frac{1-\sum_{i=1}^{j} \rho_{i}}{\mu_{j}^{D}-\lambda\left(1-\sum_{i=1}^{j} \rho_{i}\right)}\right)
\end{aligned}
$$

For this system, it is also possible to determine the average number of patent applications to be analyzed by the patent examiner and the average period of time this patent examiner takes to examine the patent applications in a specific examination stage $j$, as the following equations present:

$$
\begin{gathered}
L_{j}^{I}=\frac{\lambda\left(1-\sum_{i=1}^{j-1} \rho_{i}\right)}{\mu_{j}^{I}-\lambda\left(1-\sum_{i=1}^{j-1} \rho_{i}\right)} \\
W_{j}^{I}=\frac{\left(1-\sum_{i=1}^{j-1} \rho_{i}\right)}{\mu_{j}^{I}-\lambda\left(1-\sum_{i=1}^{j-1} \rho_{i}\right)}
\end{gathered}
$$

As the system must be balanced according to Burke's theorem, it is necessary to correlate the average input rates of patent applications of all subsystems and their related patent applications examination rates. For an examination stage $j$, the relation between the average examination rate $\mu_{j}^{\prime}$ and the average rate of new patent applications arrival in the first examination stage $\lambda$ is:

$$
\frac{\mu_{j}^{I}}{\lambda}>1-\sum_{i=1}^{j-1} \rho_{i}
$$

On the applicant side, for an answering stage $j$ of patent application analysis performed by the patent examiner, the relation between the average rate of answers to the patent application analysis performed during $j^{\text {th }}$ stage of patent examination and the rate of new patent applications arrival in the first examination stage $\lambda$ is:

$$
\frac{\mu_{j}^{D}}{\lambda}>1-\sum_{i=1}^{j} \rho_{i}
$$

Where:

$$
\sum_{j=1}^{N-1} \rho_{j} \leq 1 \quad N \leq P
$$

As can be concluded from equation 14, the relation between 
the average examination rate $\mu_{j}^{l}$ of examination stage $j$ and the average rate of new patent applications arrival in the first examination stage $\lambda$ depends on the total percentage of patent applications that are granted, denied and withdrawn until exa-mination stage $j-l$. A similar conclusion can be drawn by analyzing equation I5, which shows that the relation between the answering average rate $\mu_{j}{ }_{j}$ of the patent application analysis performed during jth stage of patent examination and the average rate of new patent applications arrival in the first examination stage $\lambda$ depends on the total percentage of patent applications that are granted, denied and withdrawn until examination stage $j$.

Once a single patent examiner shares his examination capacity among all patent examination stages, the sum of all average examination rates can be considered as the total average capacity of this patent examiner, as in the following equation:

$$
\mu^{I}=\sum_{j=1}^{P} \mu_{j}^{I}
$$

\section{Results}

To perform the analysis of patent examination effort distribution, consider two patent examiners that get to patent applications decisions by performing up to three examination stages, with a decision profile as presented in Table I and an average arrival rate of new patent applications in the first examination stage of $\lambda$, where $\lambda=3,5$.

Both patent examiners perform, on average, 10,0 patent application examinations per month, and the average examination effort distribution among the three patent examination stages for patent examiner $\_$patent examiner I $\left(\mu_{j}^{l}\right)$ and patent examiner $2\left(\mu^{2}{ }_{j}\right)_{\text {_ }}$ are presented in Table 2 .

Based on the information provided for each of the two patent examiners, not only the average number of patent applications on each examination stage $L^{1}{ }_{i}$ for patent examiner I but also the average number of patent applications on each examination stage $L^{2}{ }_{i}$ for patent examiner 2 can be determined. Table 3 presents these results.

It is also possible, based on the information provided for each of the two patent examiners, to calculate the average amount of time in months that a patent application spends on each ex- amination stage $W^{\prime}{ }_{i}$ for patent examiner $I$ and the average amount of time in months that a patent application spends on each examination stage $W^{2}{ }_{i}$ for patent examiner 2 . Table 4 presents these results.

Once the interest is to analyze the patent examiners' distribution effort, it will be considered that the applicants spend four months ${ }^{5}$ on average to answer to a patent examination. Based on this, the number of patent applications waiting for an answer after each examination stage $L^{D_{j}}$ is presented in Table 5.

By adding the total average number of patent applications for patent examiners $I$ and 2 presented in Table 3 with the total number of patent applications waiting for an answer from the applicants, it is possible to determine the total average number of patent application that are under the responsibility of each patent examiner. Likewise, by adding the total average amount of time that a patent application spends on all examination stages to the total average amount of time the applicants spend to answer all patent examinations, it is possible to determine the average period of time a patent application spends in the system until it is granted, denied or withdrawn. Table 6 presents these results.

According to the results presented in Table 6, it can be seen that patent examiner I has on average 34\% less patent applications on his responsibility than patent examiner 2 and that patent examiner I can get to a patent application decision in $35 \%$ less of the time that patent examiner 2 can get on average. Even being less efficient than patent examiner I, patent examiner 2 can process the incoming patent applications and meet the society demand as well as patent examiner I.

However, considering the decision profile presented in Table I, an average arrival rate of new patent applications in first examination stage of $3,5(\lambda=3,5)$ and an average of 10,0 patent application examinations per month, the best average examination effort distribution for a patent examiner would be the one presented in Table 7.

As a result of this average examination effort distribution, the best average number of patent application on each examination stage $L^{B}{ }_{i}$ and the best average amount of time a patent application spends on each examination stage $W^{B}{ }_{i}$ are presented in Table 8.

By adding these results to the total number of patent applications waiting for an answer from the applicants and the total a-

5 The period of four months was considered based on the Brazilian patent law, which establishes a limit of ninety days to the applicant to answer to a patent application examination. 
verage amount of time the applicants spend to answer to all patent examinations, it is possible to determine the total best result for the examination effort distribution presented in Table 9.

Comparing the best results that can be achieved with the results presented in Table 6, patent examiner I is able to improve his results up to $12 \%$ and patent examiner 2 is able to improve his results up to $34 \%$, which means that, considering the decision profile presented in Table I, an average arrival rate of new patent applications in the first examination stage of $3,5(\lambda=3,5)$ and an average of 10,0 patent application examinations per month, that is the best both of the patent examiners can do.

If we introduce a third patent examiner, considering s/he has the decision profile as in Table 6 , an average arrival rate of new patent applications in the first examination stage of $3,5(\lambda=3,5)$ and a patent examination distribution effort as presented in Table 10.

As Table 10 shows, the total average examination effort for the third patent examiner is 8,0 patent examinations per month. Considering this average examination effort distribution, the average number of patent application on each examination stage $L^{3}{ }_{i}$ for patent examiner 3 and the average amount of time a patent application spends on each examination stage $\mathrm{W}_{i}{ }_{i}$ for patent examiner 3 are presented in Table II.

Again, by adding these results to the total number of patent applications waiting for an answer from the applicants and the total average amount of time the applicants spend to answer all patent examinations, it is possible to determine the total results for the examination effort distribution of patent examiner 3 , as presented in Table 12:

Comparing now the results for patent examiner 3 with the results for patent examiner I, it can be seen that patent examiner I has on average I\% less patent applications on his responsibility than patent examiner 3 and in terms of period of time to a decision, patent examiner I can decide on average in a period of time $2 \%$ shorter than patent examiner 3 . On the other hand, patent examiner 3 has on average 33\% less patent applications on his responsibility than patent examiner 2 and in terms of period of time to a decision, patent examiner 3 can decide on average in a period of time $33 \%$ shorter than patent examiner 2, although patent examiner 2 performs on average 10,0 patent examinations per month while patent examiner 3 performs only 8,0 patent examinations per month.

\section{Discussion}

Work overload on patent offices leads to a backlog of patent applications awaiting for examination, which results in a delay in the decision whether to grant or to deny the application. This backlog causes the society to make pressure over the patent offices to optimize their internal procedures in order to increase the decision rate of patent applications. This pressure over the patent offices is reflected on the work of the patent examiners, who end up investing less time in the examination of patent applications aiming at a higher productivity, which can lead to negative impacts on the quality of the examinations and consequently on the quality of the patent granted. And, as it was previously mentioned, the granting of patents of poor quality leads to negative consequences to both patent offices and society.

As an attempt to improve the performance of the examination process without sacrificing the examination quality, this study proposes a modelling strategy to analyse the patent examination effort distribution among the patent examination stages.

This modelling strategy is based on the queuing theory and aims at simulating the entire examination process, from the moment the patent examiners begin examining a patent application to the moment it is granted or denied by the patent office or withdrawn by the applicants. This model considers that the examination process of a patent application is performed by only one patent examiner in a series of examination stages, and that after each examination stage the applicants have the opportunity to answer the patent examiner and provide subsidies to the pursuit of the examination process. Once a single patent examiner is responsible for the analysis of patent application through several examination stages, he/she must distribute his/her examination capacity among the examination stages, given a decision profile for this patent examiner and an average rate of new patent applications arrival in the first examination stage. Without any kind of formal orientation, this patent examiner may distribute his/her examination capacity based on heuristic criteria, which means that he/she may not be as productive as he/she could be.

Based on the results achieved by applying this mathematical model, it is possible to conclude that, because of a different distribution of the patent examiner examination effort among the examination stages, a patent examiner can be significantly more efficient than others. This means that the patent examiner will have on his responsibility, on average, a smaller number of patent applications once he is able to make a decision for a patent application, on average, in a shorter period of time without performing any additional examination effort.

It is also possible to conclude that, based on a specific decision profile, there is a best patent examination effort distribution, given the total average patent examination capacity, which means that a patent examiner can not improve his performance beyond a certain limit. 
Finally, the results also show that when a patent examiner performs more patent examinations per unit of time, he is not necessarily being more efficient, once the distribution of his examination capacity among the patent examination stages may not be efficient. This means that another patent examiner, even by performing less patent examinations per unit of time, can be more efficient than this first one, if he distributes his examination capacity more efficiently.

As a conclusion of this study, this modelling strategy can be applied in any patent office that follows these examination procedures in order to improve its productivity only by guiding the patent examiners to properly distribute their analysis capacity among the examination stages, which would lead to the reduction of the backlog in the offices, meeting the society demand.

\section{References}

BARTON, J. H. (2000) 'Reforming the Patent System', Science, Vol. 287: pp. 1933-1934.

BATABYAL, A. A., DeAngelo, G. J. (2008) 'Average Patent Pendency and Examination Errors: A Queuing Theoretic Analysis', International Journal of Foresight and Innovation Policy, Vol. 4, pp. I I2-I 28.

BATABYAL,A.A., Nijkamp, P. (2008) 'Is There a Tradeoff Between Average Patent Pendency and Examination Errors?', International Review of Economics and Finance, Vol. I7, pp. I50-I 58.

BOSE, S. K. (2002), Open and Closed Networks of M/M/m Type Queues (Jackson's Theorem for Open and Closed Networks), Obtained through the Internet: http://home.iitk.ac.in/ skb/ qbook/Slide_Set_I4.PDF, [accessed in 26/02/2008].

Brazilian Federal Law Number 9.279 (1996).

European Patent Office (EPO) (2007), European Patent Convention, I3th Edition.

European Patent Office (EPO (2008)), European Patents Applications 1990-2006. Obtained through the Internet: http://www.epo.org/about-us/office/statistics/applications1990-2006.html, [accessed in 30/06/2008].

General Accounting Office (GAO) (1996) 'Enhancements Needed In Computing and Reporting Patent Examination Statistics, Report to the Chairman', Committee on the Judiciary (U.S. Senate, Washington, DC).

GRAHAM, S.J.H., Hall, B.H., Harhoff, D., Mowery, D.C. (2003) Patent Quality Control? A Comparisons of U.S. Patent Re-ex- aminations and European Patent Oppositions, Wesley M. Cohen and Stephen A. Merrill eds., Patents in the Knowledge-Based Economy, National Academy Press, Washington, D.C., Pp. 74119.

HALL, B. H., Ziedonis, R. H. (200I) 'The Patent Paradox Revisited: An Empirical Study of Patenting in the U.S. Semiconductor Industry, 1979- 1995', Rand Journal of Economics, Vol. 32: pp. I0I-I 28.

KING, J. L. (200I) Patent Examination Procedures as Inputs to Patent Quality. New Research on the Operation and Effects of the Patent System, National Academy of Sciences Committee on Science, Technology and Economic Policy.

KING, J. L. (2003), Patent Examination Procedures and Patent Quality, Wesley M. Cohen and Stephen A. Merrill eds., Patents in the Knowledge-Based Economy, National Academy Press, Washington, D.C., pp. 54-73.

MEURER, M. J (1989). 'The Settlement of Patent Litigation', RAND Journal of Economics, Vol.20(I) (Spring): pp. 77-9I.

PHILLIP, M. (2006) 'Patent filing and searching: Is deflation in quality the inevitable consequence of hyperinflation in quantity ?', World Patent Info, Vol. 28, pp. I I7-I2I.

POPP, D., Juhl, T., Johnson, D.K.N. (2004) 'Time In Purgatory: Examining the Grant Lag for U.S. Patent Applications', Topics in Economic Analysis \& Policy, Article 29,Volume 4, Issue I.

ROSS, S.M. (2003) Introduction to Probability Models, 8th edition. Academic Press, San Diego, California.

SINGH, V.K. (2007) 'Fundamentals of Patent Pendency and Its Calculation', Ezine Articles. Obtained through the Internet: http://ezinearticles.com/?Fundamental-of-Patent-Pendency-andIts-Calculation\&id=846849. [accessed in 16/02/2008].

United States Patent and Trademark Office (USPTO) (2007), Manual of Patent Examining Procedure (MPEP) - United States Code Title 35 - Patents, Appendix L, Patent Laws. 


\section{Appendix}

Table 1

Decision profile per examination stage

\begin{tabular}{|l|l|l|l|}
\hline Examination stage & $1^{\text {st }}$ & $2^{\text {nd }}$ & $3^{\text {rd }}$ \\
\hline$\rho_{\mathrm{i}}$ & $45 \%$ & $35 \%$ & $20 \%$ \\
\hline
\end{tabular}

Table 2

Average examination effort distribution

\begin{tabular}{|c|c|c|c|}
\hline Examination stage & $1^{\text {st }}$ & $2^{\text {nd }}$ & $3^{\text {rd }}$ \\
\hline Patent examiner $1\left(\mu^{1_{i}}\right)$ & 4,0 & 4,0 & 2,0 \\
\hline Patent examiner $2\left(\mu^{2}\right)$ & 6,0 & 2,0 & 2,0 \\
\hline
\end{tabular}

Table 3

Average number of patent application on each examination stage

\begin{tabular}{|c|c|c|c|c|}
\hline Examination stage & $1{ }^{\text {st }}$ & $2^{\text {nd }}$ & $3^{\text {rd }}$ & TO TAL \\
\hline Patent examiner $1\left(\mathrm{~L}_{\mathrm{i}}\right)$ & 7,0 & 0,9 & 0,5 & 8,4 \\
\hline Patent examiner $2\left(\mathrm{~L}_{\mathrm{i}}\right)$ & 1,4 & 25,7 & 0,5 & 27,6 \\
\hline
\end{tabular}

Table 4

Average amount of time a patent application spends on each examination stage

\begin{tabular}{|c|c|c|c|c|}
\hline Examination stage & $1^{\text {st }}$ & $2^{\text {nd }}$ & 3rd & TO TAL \\
\hline Patent examiner $1\left(\mathrm{~W}_{1_{\mathrm{i}}}\right)$ & 2,0 & 0,3 & 0,2 & 2,5 \\
\hline
\end{tabular}

ISSN : 0718-2724. (http://www.jotmi.org)

JOURN AL OF TECHN OLOGY MAN AGEMENT\& IN N O VATION C JOTMI Research Group 
Table 5

\begin{tabular}{|l|l|l|l|l|} 
Patent examiner $2\left(\mathrm{~W}_{\mathrm{i}}\right)$ & 0,4 & 7,3 & 0,2 & 7,9 \\
\hline
\end{tabular}

Average amount of patent applications waiting for an answer after each examination stage

\begin{tabular}{|c|c|c|c|}
\hline After examination stage & $1^{\text {st }}$ & $2^{\text {nd }}$ & TO TAL \\
\hline A pplicant $\left(\mathrm{LD}_{\mathrm{i}}\right)$ & 14,0 & 14,0 & 28,0 \\
\hline
\end{tabular}

Table 6

Total results for each patent examiner

\begin{tabular}{|c|c|c|}
\hline Parameter & L & W \\
\hline Patent examiner 1 & 36,4 & 10,5 \\
\hline Patent examiner 2 & 55,6 & 15,9 \\
\hline
\end{tabular}

\section{Table 7}

Best average examination effort distribution

\begin{tabular}{|c|c|c|c|}
\hline Examination stage & $1^{\text {st }}$ & $2^{\text {nd }}$ & $3^{\text {rd }}$ \\
\hline Best average examination effort distribution & 5,3 & 3,2 & 1,5 \\
\hline
\end{tabular}

\section{Table 8}

The best average number of patent applications on each examination stage and the best average amount of time a patent application spend on each examination stage

\begin{tabular}{|c|c|c|c|c|}
\hline Parameter & $1^{\text {st }}$ & $2^{\text {nd }}$ & $3^{\text {rd }}$ & TO TAL \\
\hline $\mathrm{L}_{\mathrm{i}}$ & 1,9 & 1,5 & 0,9 & 4,3 \\
\hline $\mathrm{W} \mathrm{B}_{\mathrm{i}}$ & 0,6 & 0,4 & 0,2 & 1,2 \\
\hline
\end{tabular}

ISSN : 0718-2724. (http://www.jotmi.org) 
Table 9

Total results for the best average examination effort distribution

\begin{tabular}{|c|c|c|}
\hline Parameter & L & W \\
\hline Best average examination effort distribution & 32,3 & 9,2 \\
\hline
\end{tabular}

Table 10

Average examination effort distribution for a third patent examiner

\begin{tabular}{|c|c|c|c|}
\hline Examination stage & $1^{\text {st }}$ & $2^{\text {nd }}$ & $3^{\text {rd }}$ \\
\hline Patent examiner $3\left(\mu^{3_{i}}\right)$ & 4,5 & 2,5 & 1,0 \\
\hline
\end{tabular}

Table 11

Average number of patent application on each examination stage and average amount of time a patent application spend on each examination stage for patent examiner 3

\begin{tabular}{|c|c|c|c|c|}
\hline Parameter & $1^{\text {st }}$ & $2^{\text {nd }}$ & 3rd & TO TAL \\
\hline $\mathrm{L}_{\mathrm{i}}$ & 3,5 & 3,4 & 2,3 & 9,2 \\
\hline $\mathrm{W}_{\mathrm{i}}$ & 1,0 & 1,0 & 0,7 & 2,7 \\
\hline
\end{tabular}

\section{Table 12}

Total results for patent examiner 3

\begin{tabular}{|c|c|c|}
\hline Parameter & L & W \\
\hline Patent examiner 3 & 37,2 & 10,6 \\
\hline
\end{tabular}

ISSN : 0718-2724. (http://www.jotmi.org) 


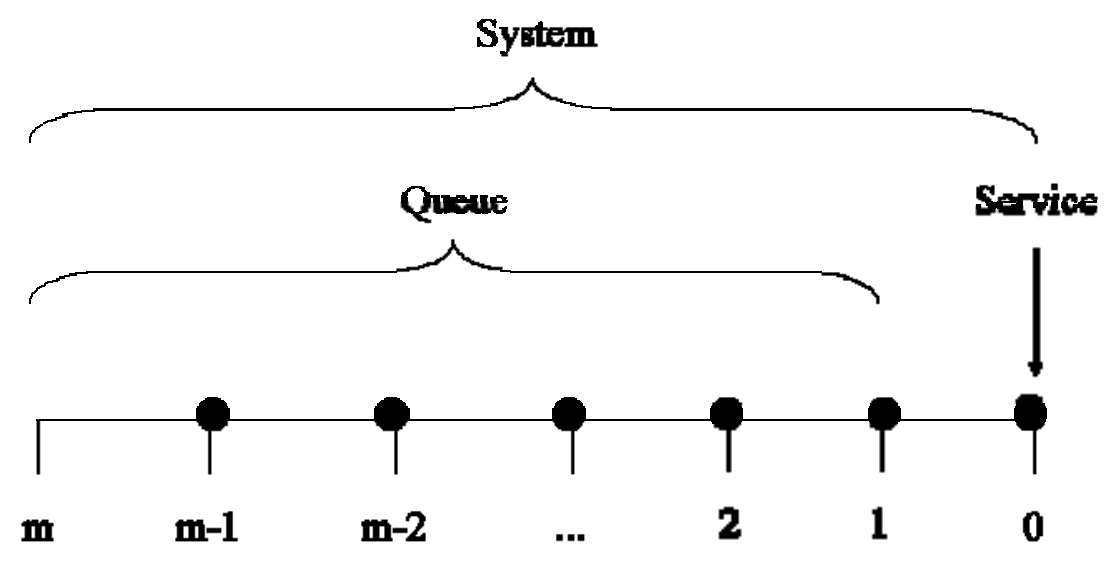

Figure 1. System according to the queuing theory.

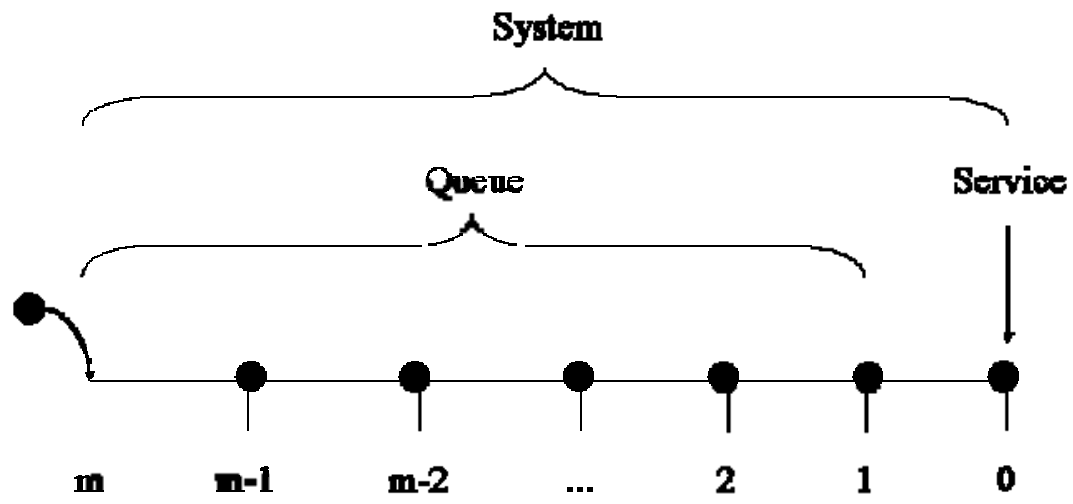

Figure 2. Customer arrival process for a single server system.

\section{System}
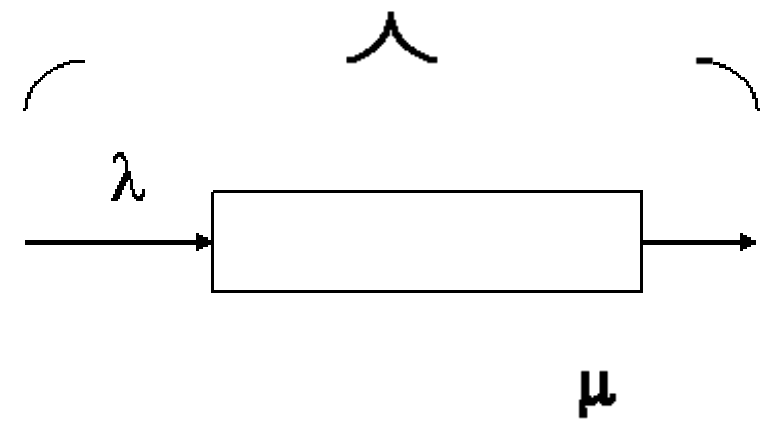

ISSN : 0718-2724. (http://www.jotmi.org)

JO URNAL OF TECHNOLOGY MANAGEMENT\& IN NOVATION C JOTMI Research Group 
Figure 3. M/M/1 open system.

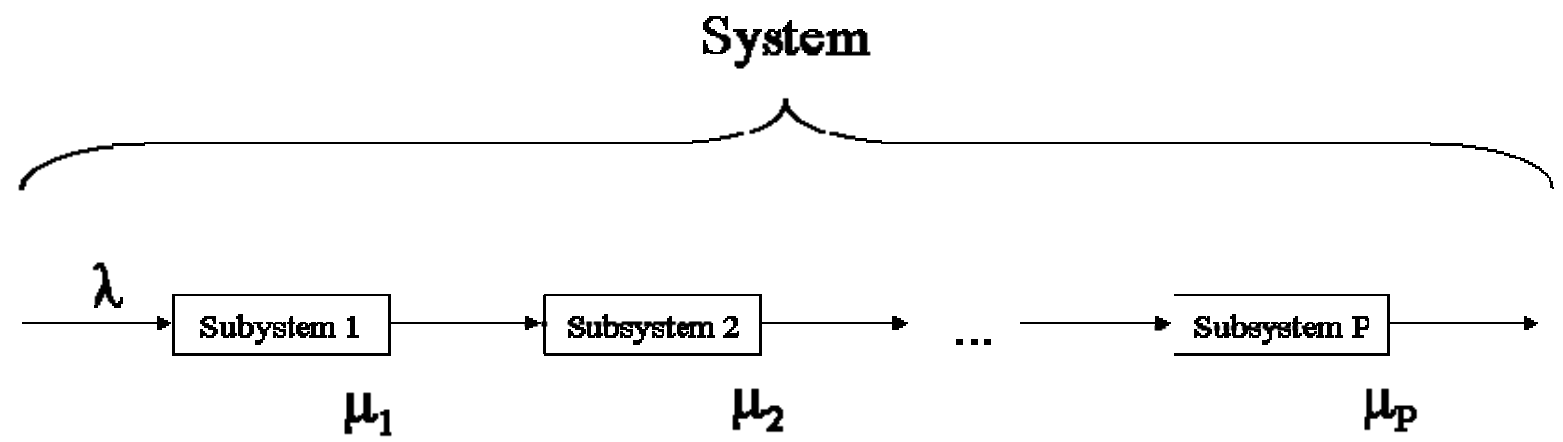

Figure 4. System of $P M / M / 1$ open subsystems.

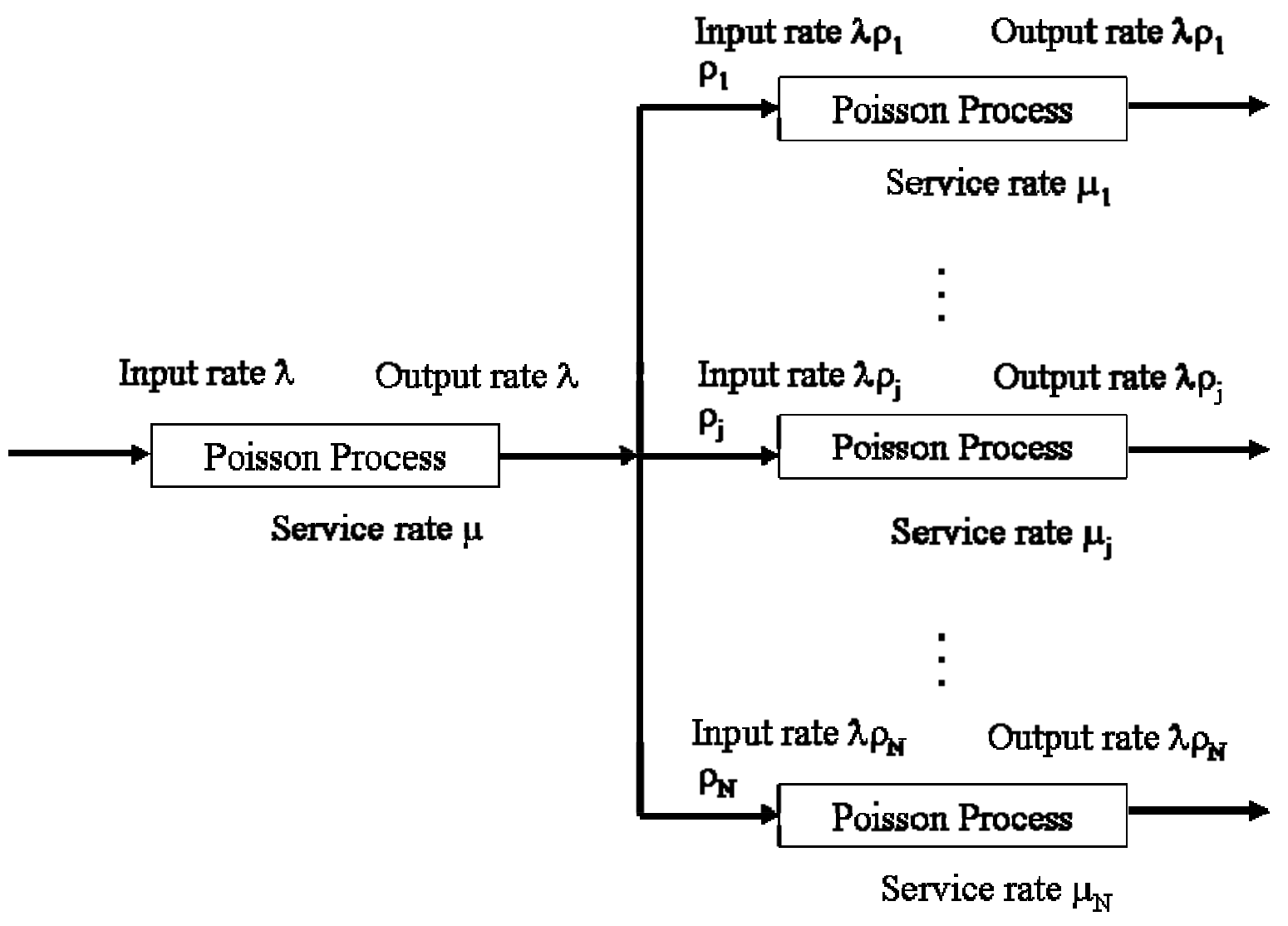

Figure 5. Burke's theorem applied to a division of a Poisson process. 


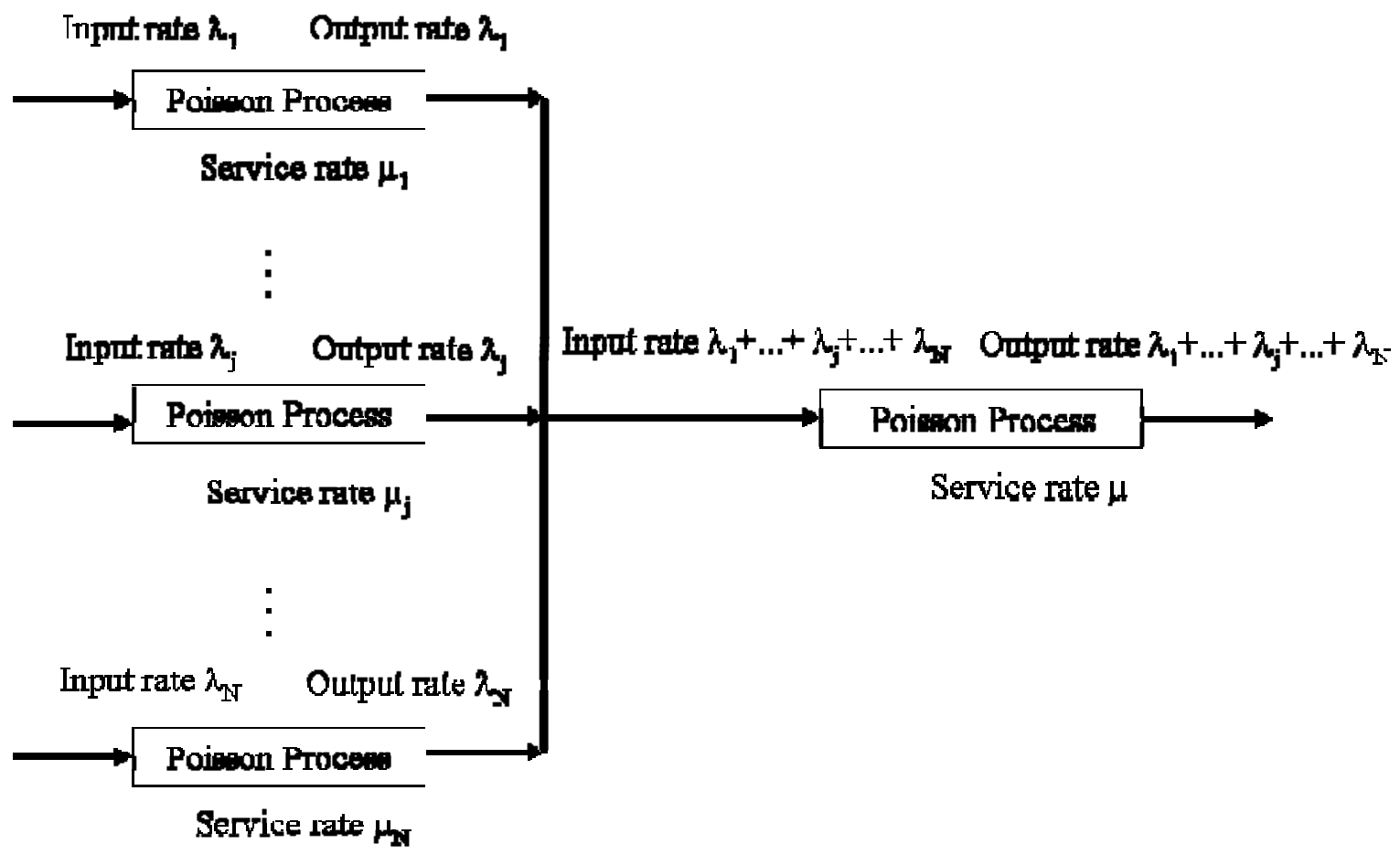

Figure 6. Burke's theorem applied to a combination of Poisson processes.

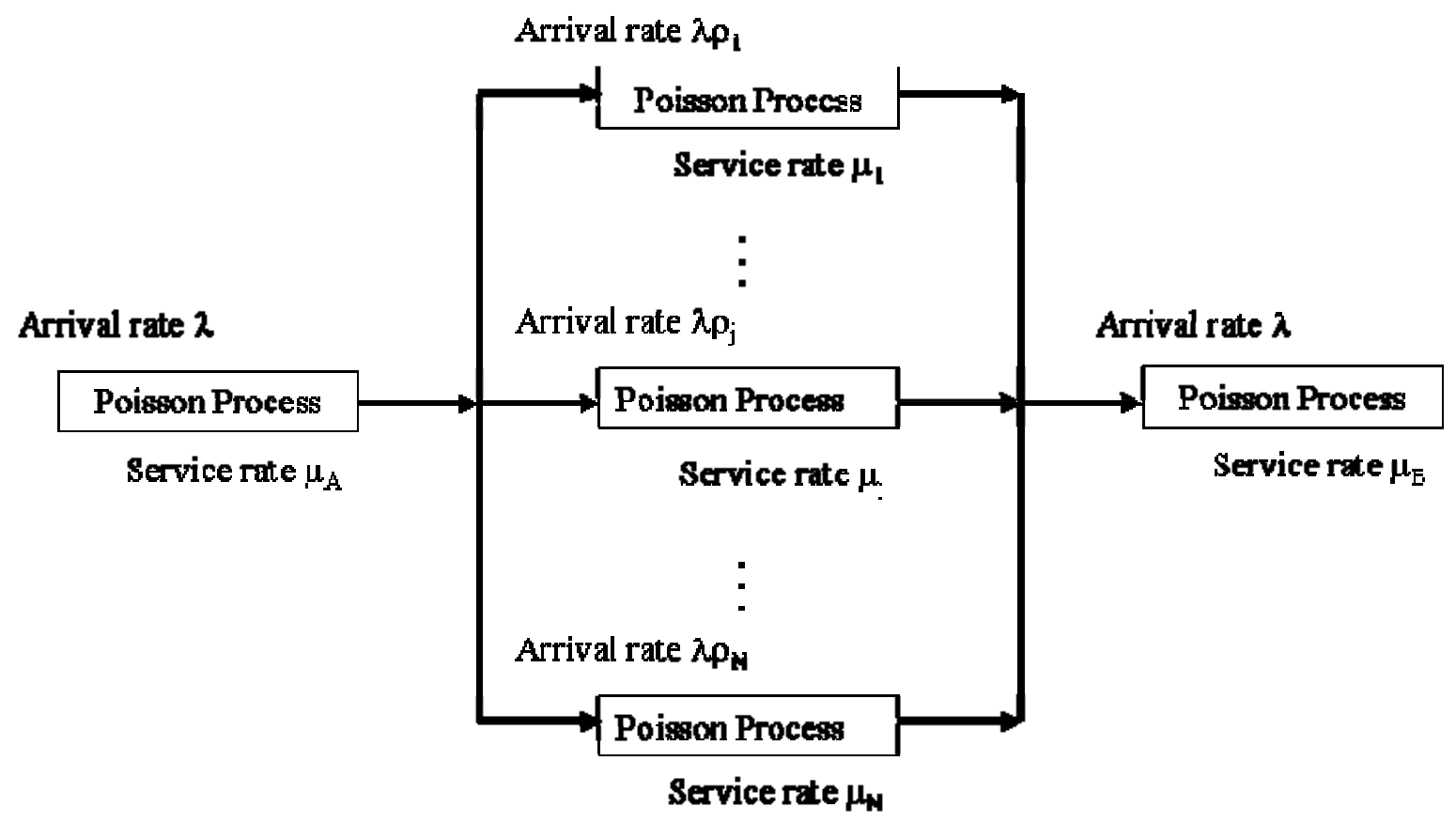

Figure 7. Parallel Poisson processes. 
Arrival rate $\lambda$

Poisson Process

Service rate $\mu_{A}$
Arrival rate $\lambda$

\section{Poisson Process}

Service rate $\mu_{\text {EC }}$
Arrival rate $\boldsymbol{\lambda}$

Poisson Process

Service rate $\mu_{E}$

Figure 8. Single Poisson process as an equivalent of several parallel Poisson processes.
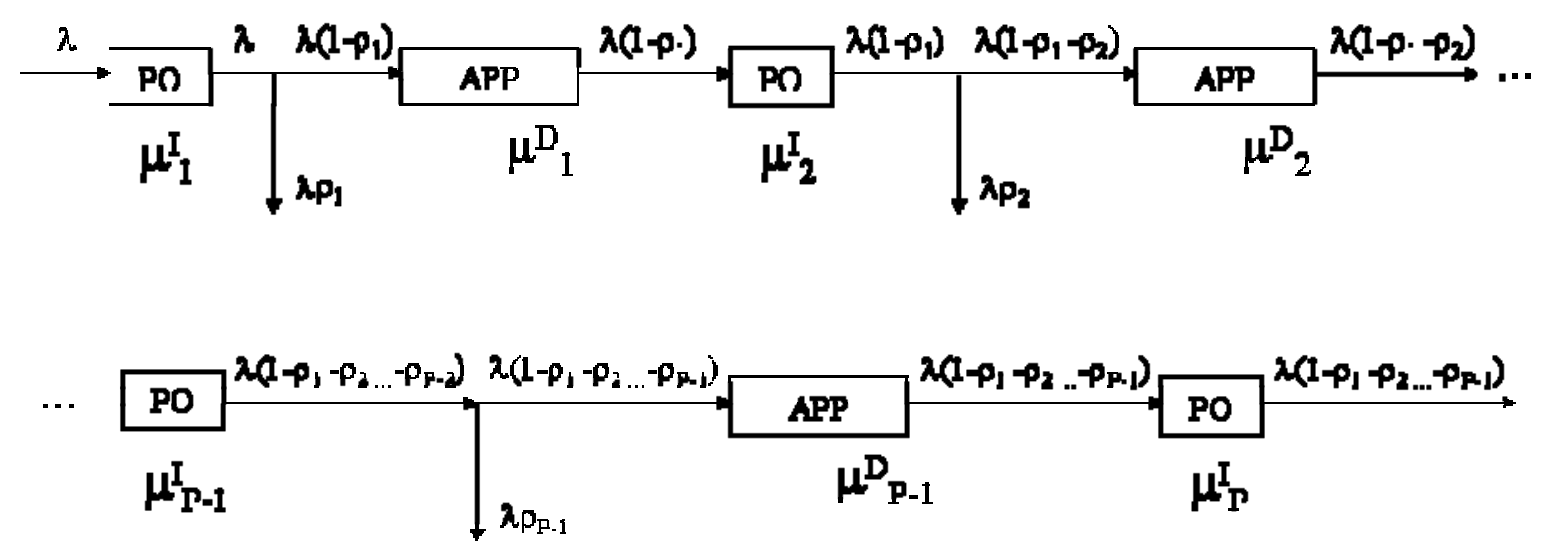

Figure 9. Q ueuing theory applied to patent examination. 